Title page

Article title:

Increasing prevalence of asthma, allergic rhinoconjunctivitis and eczema among schoolchildren: Three surveys during the period1985-2008.

Author's names and institutional affiliations:

1. Tonje Elisabeth Hansen, MD

Division of Pediatrics, Obstetrics and Woman's Health, Nordland Hospital, Bodø, Norway

2. Bjørg Evjenth, MD

Division of Pediatrics, Obstetrics and Woman's Health, Nordland Hospital, Bodø, Norway

3. Jan Holt MD, PhD

a) Division of Pediatrics, Obstetrics and Woman's Health, Nordland Hospital, Bodø, Norway

b) Institute of Community Medicine, University of Troms $\varnothing$, Troms $\varnothing$, Norway

Short title:

Asthma, allergic rhinoconjunctivitis and eczema prevalence in schoolchildren in a subarctic population.

Corresponding author: Tonje Elisabeth Hansen

Division of Pediatrics, Obstetrics and Woman's Health, Nordland hospital, Post box 1480, 8092 Bodø, Norway,

mailto: tonje.elisabeth.hansen@ @lsh.no, Phone: +47 97080673, Fax: + 4775534013 


\section{Authors Contributions}

TEH: Designed the study, collected data, analyzed data and wrote the article.

BE: Analyzed data and wrote the article.

JH: Designed the study analyzed data and revised the article critically.

\section{Conflict of interests}

The authors declare no conflicts of interest in respect to the authorship and/or publication of this article. 


\begin{abstract}
Aim: The prevalence of asthma, allergic rhinoconjunctivitis (AR) and eczema among children has increased worldwide in the last four decades, but recent studies disagree as to whether the prevalence is continuing to rise or is leveling off or declining. The aim of this study was to assess time trends in a subarctic population.
\end{abstract}

Methods: A cross-sectional, questionnaire-based survey was carried out in 2008 among children aged 7-14 years in random selected schools in Nordland County, Norway $(n=4150)$. The results are compared with results from identical studies in $1985(\mathrm{n}=4870)$ and $1995(\mathrm{n}=4456)$.

Results: The main findings were an increasing prevalence of asthma ever $(7.3 \%$ in 1985 to $17.6 \%$ in 2008 , $\mathrm{p}$ for trend < 0.001$)$ and AR ever $(15.9 \%$ in 1985 to $24.5 \%$ in 2008, $\mathrm{p}$ for trend $<0.001$ ), while the prevalence of eczema ever, after an increase between 1985 and 1995, remained unchanged in the last time period. The prevalence of current disease doubled and trebled between 1995 and 2008 for all three diseases.

Conclusion: A repeated cross-sectional survey between 1985-2008 documented an increasing prevalence of asthma ever and AR ever among schoolchildren (7-14 years), together with a considerably increase in current asthma, AR and eczema between 1995-2008. 
Keywords: allergic rhinoconjunctivitis, asthma, prevalence, schoolchildren, time trends

Keynotes:

Repeated cross-sectional surveys between 1985-2008 demonstrated an increase in the prevalence of asthma and allergic rhinoconjunctivitis ever among school children (714 years) in a subarctic population, while the prevalence of eczema ever leveled off. Between 1995-2008 the prevalence of current disease increased substantially in all three diseases. 


\section{Introduction}

In recent decades the prevalence of asthma and allergic diseases has increased substantially, and today asthma is the most frequent chronic disease among children in developed countries (1). This imposes a considerable burden of disease on patients, health care systems and society. Whereas some studies still demonstrate an increasing prevalence of asthma and allergic disease (2-4), other reports indicate a leveling off or even a decrease in the prevalence (5-7). Results from the ISAAC phase III study (2000-2003) indicate that the difference in asthma symptom prevalence between developed and developing countries has fallen (8). In spite of this change, the prevalence of asthma, allergic rhinoconjunctivitis (AR) and eczema shows wide global variation (9). The diverse global trends make regional repeated investigations important to assess time trends. Local surveys provide information about geoclimatic variables and topographical factors that may affect disease prevalence (10). In the northern part of Norway a questionnaire-based, crosssectional survey of asthma and allergic disease was performed in 1985 (11) and repeated 10 years later: The lifetime prevalence of asthma and allergic diseases increased over this period (12). Thus, the objective of the current study was to explore whether or not the prevalence of asthma, AR and eczema continued to increase in a population of children in a subarctic area.

\section{Subjects and Methods}

\section{Study area}

The Northern part of Norway consists of three counties: Nordland, Troms and Finnmark, with a subarctic population of 468251 inhabitants (13). Nordland County, 
which covers an area of $37000 \mathrm{~km}^{2}$, has a unique geography with a long coastline, half of it located north of the Arctic Circle. The subarctic climate in Nordland displays an average yearly temperature of 5-6 degrees Celsius and a yearly amount of precipitation (rainfall) of 3000 millimeters.

\section{The questionnaire}

A questionnaire focusing on diagnosis and symptoms of asthma, AR and eczema was created in 1985 to assess disease among schoolchildren in northern Norway. Questions covered gender, age, family history of atopy, socio-economic conditions, passive smoke exposure and household animals. The questionnaire was completed by parents/guardians who also signed a written consent for their children's participation. The questionnaire has been used in other Norwegian studies $(14,15)$, and its validity has been evaluated. The questionnaire-based diagnosis of asthma was found to have a sensitivity of 0.96 and a specificity of 0.88 (14).

\section{The 1985 and 1995 studies}

The questionnaire was distributed to schoolchildren aged 7-13 years in randomly selected schools in northern Norway in 1985 and 1995. The local school nurse distributed the questionnaires and passed a new questionnaire to those not responding. The questionnaires were completed by $95 \%$ in 1985 and by $87 \%$ in 1995. The 1995 study included additional questions concerning symptoms and diseases during the last 12 months (current diseases), but was otherwise identical. The 1985 and 1995 surveys are described in detail elsewhere $(11,12)$. 
The 2008 study

In 2008, we used identical questions to those used before adding questions about physical activity, medical diagnose of asthma and asthma medication. The additional questions did not change the definition of the diseases. Schoolchildren aged 7-14 years from 65 randomly selected schools out of a totally 244 schools in Nordland County were invited to participate. These 65 schools represent 31 of 44 municipalities (local authorities) in the County. The pupils received the questionnaire between February and May. This time we were not allowed from the Regional Committee for Medical and Healthcare Research to send personal reminders. Thus all participants received one reminder. The study closed four weeks after the reminder was distributed.

\section{Definitions}

'Asthma ever' was considered if the parent answered 'yes' to the question: Has the pupil ever had asthma (question 1)? and/or to the question: Does the pupil experience wheeze, periods of coughing or acute shortness of breath (asthma) due to external factors (question 2)?

'Allergic Rhinoconjunctivitis (AR) ever' was estimated on the basis of a positive answer to the question: Has the pupil ever had hay fever (runny or blocked nose, sneezing, itching of the nose and/or eyes, or swollen or red eyes)?

'Eczema ever' was recorded if the pupils reported an itchy rash lasting at least four weeks combined with lesions on the face, elbows or knee flexures, or a high degree of itching and lesions elsewhere. 
'Current disease' was considered among those answering yes to the main questions about asthma, AR or eczema and reporting symptoms the last 12 months.

Atopic disease among family members was defined when answering yes to the question: Does anyone in the family suffer from asthma, hay fever, eczema, urticaria or other diseases you believe are caused by allergy? The answers specified which family members (parents and or siblings) and which disease they were suffering from.

\section{Statistical analyses}

The main outcome was differences in prevalence between the periods $1985-95$ and 1995-2008. The analyses were performed using chi-square statistics, and the differences in secular prevalence were quantified with odds ratios (OR). For values measured three times, chi-square test for trend (linear-by-linear associations) was calculated. P-values below 0.05 were considered statistically significant in all analyses, and they were accompanied by a $95 \%$ confidence interval (95\% CI). Only a few missing values to the main questions about asthma, AR and eczema $(0.3 \%, 1.0 \%$ and $0.7 \%$ respectively) were found. The missing values were considered to be nonconfirmative. The statistical analyses were performed using Graph Pad Prism version 5 (Graphial Software, San Diego Ca, USA) and Statistical Package for Social Science (SPSS) software version 19.0 (SPSS Inc. IBM, Chicago, IL, USA).

\section{Ethical approval}

The study protocol was approved by the Regional Committee for Medical and Healthcare Research, Northern Norway and The Norwegian Data Inspectorate. 


\section{Results}

Of 6505 pupils invited to participate, 4150 (64\%) were enrolled in the study $(49.1 \%$ boys). The demographic data of all three surveys are given in Table 1 .

\section{Asthma}

The prevalence of asthma ever increased from $7.3 \%$ in 1985 to $17.6 \%$ in 2008 (p for trend $<0.001$ ) (Table 2). The prevalence of asthma ever was significantly higher among boys compared to girls in all three surveys: In 1985 8.9\% vs. 5.5\% (OR 1.68, 95\% CI: 1.34-2.10), in 1995 14.5\% vs. $10.3 \%$ (OR 1.48; 1.23-1.77) and in 2008 $21.4 \%$ vs. $13.9 \%$ (OR 1.68; 1.43-1.98). Current asthma increased from $4.8 \%$ to $9.9 \%$ between 1995 and 2008 (Table 3). In 2008 doctor diagnosed asthma ever was reported by $13.8 \%$ of the participants, asthma medication ever by $18.5 \%$ and asthma medication used the last year by $8.2 \%$ of the participants.

\section{Allergic rhinoconjunctivitis $(A R)$}

The prevalence of AR ever increased between 1985 and 2008 ( $\mathrm{p}$ for trend $<0.001$ ) (Table 2). The prevalence of AR ever was significantly higher among boys compared to girls in all three surveys: In 1985 18.2\% vs. 13.4\% (OR 1.43; 1.23-1.68), in 1995 $24.6 \%$ vs. $18.3 \%$ (OR $1.48 ; 1.28-1.71$ ) and in $200827.9 \%$ vs. $21.2 \%$ (OR $1.43 ; 1.24-$ 1.65). Current AR increased threefold between 1995 and 2008 (Table 3). 
The prevalence of eczema ever increased in the first time period and remained unchanged in the last period (Table 2). The prevalence of eczema ever was approximately similar between girls and boys in 1985 (12.8\% vs. $11.7 \%$, OR 1.1; 0.93-1.32), but higher among girls in 1995 and 2008 (OR 1.43; 1.23-1.68 and OR $1.48 ; 1.28-1.71$, respectively). The prevalence of current eczema was more frequent in 2008 in both genders (Table 3).

The atopic burden and potential confounding factors

An increasing part of the responders reported a family history of atopy, parental asthma and parental allergy (Table 1). In $198521.8 \%$ of the children reporting atopic disease in the family had asthma, AR and/or eczema. This proportion increased to $50.6 \%$ in 2008 ( $\mathrm{p}$ for trend $<0.001$ ). Passive smoke exposure decreased from $60.7 \%$ to $31.9 \%$ ( $\mathrm{p}$ for trend $<0.001$ ), while the number of households keeping pet animals remained unchanged (56.3\% in 1985 vs. $56.0 \%$ in 2008).

\section{Co-morbidity}

The proportion of children reporting at least one disease (asthma, AR or eczema) increased from $26.2 \%$ in 1985 to $43.3 \%$ in 2008 ( $\mathrm{p}$ for trend < 0.001 ). The proportion of children with all three diseases and the proportion of children with both asthma and eczema increased during the study period (Table 4). The proportion of children reporting the combination of asthma and AR or AR and eczema increased in the first time period, but stayed unchanged in the last period (Table 4). 


\section{Discussion}

The main findings in the present study were an increasing prevalence of asthma ever and AR ever, while the prevalence of eczema ever, after increasing between 1985 and 1995, stayed unchanged in the last time period. The prevalence rates found in 2008 are similar to those shown in the Norwegian birth cohort study, Oslo (2), but somewhat higher compared to results in the OLIN studies (Obstructive Lung Disease in northern Sweden) $(16,17)$. In spite of an increasing prevalence of asthma ever, data from the last time period indicated a peak in asthma symptoms. The divergent prevalence of asthma symptoms and asthma diagnosis are consistent with data from other Nordic reports $(7,18)$. In contrast to several prevalence studies in comparable populations $(2,9,19)$ we demonstrated a substantial increase in the proportion of children reporting current diseases in the last time period.

Atopic disease in the family is an important risk factor for developing asthma, AR and/or eczema $(16,20,21)$. Increased atopic burden among family members is evident. Two-thirds of the children in the 2008 survey had parents and/or siblings with atopic diseases, along with a doubling of parental asthma and allergy between 1985 and 2008. The proportion of children suffering from asthma, AR and/or eczema confirming atopic disease in the family more than doubled during the study period. Asthma, AR and eczema are closely related $(2,22)$. Still we found a leveling off in the co-morbidity of asthma and AR, while the co-morbidity of asthma and eczema increased. This pattern is in line with the findings in a recent report from the ISAAC study (23). 
Male gender is a risk factor for asthma and allergy among children $(7,24)$. We detected a male predominance, which is in line with the results found by Anthracopoulos et al. (25). Whereas the results for asthma and AR revealed a male dominance through the study period, the results for eczema demonstrated a higher proportion of girls in the last two surveys. A study from Larsson et al. (21) supports these findings. Thus the unchanged prevalence of eczema ever in the last time period might be due to an unchanged prevalence in girls.

Local environmental factors might be important contributors to different disease prevalence (9). Passive smoke exposure decreased sizeable from 1985 to 2008. Since second hand smoke exposure is associated with both the development of asthma and more severe disease, the decrease might be expected to lower the prevalence of asthma (26). Most of the study population lives in a cold, coastal climate. During wintertime the amount of indoor time is higher in a subarctic population. Weiland and colleges have proposed a negative effect of the annual variation of temperature and relative humidity outdoors on asthma and eczema symptoms (27).

The use of identical study design and questionnaires in three surveys has allowed us to assess a valid estimate of time trends for self-reported atopic diseases. The reliability of the results of studies based on questionnaires can be questioned. However self-reported symptom history conducts the necessary basis for defining asthma in epidemiological studies $(10,28)$. Repeated surveys in the same population are as close a proxy, as it was possible to attain of longitudinal data. In contrast to the ISAAC studies, we compared data from the same population during three decades, 
which formed the basis of more valid time trends. Still the time interval between the last two surveys might have been too long to detect a plateau in disease prevalence. Thus, the need of follow-up surveys in due time is evident. Questions about current symptoms are more reliable than questions about symptoms ever due to less recall bias and might give a better estimate of time trends. The proportions of children reporting use of asthma medication ever and last year are not different from the prevalence of asthma ever and current asthma, which strengthen the results.

Allergic diseases are given significant public health and media attention in Western societies. The impact of increased general awareness has been proposed in several papers to explain the increasing trend in the prevalence of allergic diseases (10). Increased awareness among health professionals and parents might have influenced the time trends in our study, and the increased atopic burden might represent a selection bias. Parents suffering from these diseases are expected to be more positive to participate and to be more aware of symptoms and diseases. Thus it is a possibility that the increase in heredity and disease prevalence might partly be due to this selection bias. The response rate of $64 \%$ in 2008 is lower than in the previous surveys, and might entail a potential selection bias. In 2008 we were not allowed to give personal reminders to the participants. We believe this represent the main cause of the lower response rate compared to the earlier surveys. It was not possible to perform any analysis of the non-responders. However a large postal survey in Sweden by Rönmark et al concluded that non-responders did not differ significantly in the prevalence of airway diseases or symptoms compared with responders (29). Thus response bias is unlikely to have seriously affected the results. As we included 
a large, representative fraction of the population from randomly selected schools in Nordland we believe the external validity of our study to be high.

In conclusion the prevalence of asthma ever and AR ever in a subarctic children population increased substantially between 1985 to 2008, while the prevalence of eczema ever reached a plateau. The doubling and tripling of current asthma, eczema and $\mathrm{AR}$ in the latest study period raises questions why and provide the basis of further investigation.

\section{Acknowledgments}

The authors wish to express gratitude to the children, parents and school nurses participating in our study “ Asthma and allergic diseases among schoolchildren in Nordland". We want to thank Dr. Sandy Goldbeck-Wood for critically revising the article. In particular we want to thank Anders Selnes and Roald Bolle for sharing the data from the 1995 survey. 


\section{References}

1. Sennhauser FH, Braun-Fahrländer C, and Wildhaber JH. The burden of asthma in children: a European perspective. Paediatr Respir Rev. 2005; 6: 2-7.

2. Lødrup Carlsen KC, Håland G, Devulapalli CS, Munthe-Kaas M, Pettersen M, Granum B, et al. Asthma in every fifth child in Oslo, Norway: a 10-year follow up of a birth cohort study. Allergy. 2006; 61: 454-60.

3. Anandan C, Nurmatov U, van Schayck OC, and Sheikh A. Is the prevalence of asthma declining? Systematic review of epidemiological studies. Allergy. 2010; 65: 152-67.

4. Gershon AS, Guan J, Wang C, and To T. Trends in asthma prevalence and incidence in Ontario, Canada, 1996-2005: a population study. Am J Epidemiol. 2010; 172: $728-36$.

5. Zöllner IK, Weiland SK, Piechotowski I, Gabrio T, von Mutius E, Link B, et al. No increase in the prevalence of asthma, allergies, and atopic sensitisation among children in Germany: 1992-2001. Thorax. 2005; 60: 545-8.

6. Akinbami LJ, Moorman JE, Garbe PL, and Sondik EJ. Status of childhood asthma in the United States, 1980-2007. Pediatrics. 2009; 123: 131-45.

7. Bjerg A, Sandström T, Lundbäck B, and Rönmark E. Time trends in asthma and wheeze in Swedish children 1996-2006: prevalence and risk factors by sex. Allergy. 2010; 65: 48-55.

8. Pearce N, Aït-Khaled N, Beasley R, Mallol J, Keil U, Mitchell E, et al. Worldwide trends in the prevalence of asthma symptoms: phase III of the International Study of Asthma and Allergies in Childhood (ISAAC). Thorax. 2007; 62: 758-66.

9. Asher MI, Montefort S, Björkstén B, Lai CK, Strachan DP, Weiland SK, et al. Worldwide time trends in the prevalence of symptoms of asthma, allergic rhinoconjunctivitis, and eczema in childhood: ISAAC Phases One and Three repeat multicountry cross-sectional surveys. Lancet. 2006; 368: 733-43.

10. von Hertzen L, and Haahtela T. Signs of reversing trends in prevalence of asthma. Allergy. 2005; 60: 283-92.

11. Holt, J, and Bolle, R. Prevalence of atopic diseases: a survey of schoolchildren in a Norwegian county. Proc Paediatr Respir Dis. 1993; 122: 00.

12. Selnes A, Bolle R, Holt J, and Lund E. Cumulative incidence of asthma and allergy in north-Norwegian schoolchildren in 1985 and 1995. Pediatr Allergy Immunol. 2002; 13: 58-63.

13. Population . http://statbank.ssb.no. 2010. 
14. Steen-Johnsen J, Bolle R, Holt J, Benan K, and Magnus P. Impact of pollution and place of residence on atopic diseases among schoolchildren in Telemark County, Norway. Pediatric Allergy and Immunology. 1995; 6: 192-199.

15. Dotterud LK, Odland JØ, and Falk ES. Atopic dermatitis and respiratory symptoms in Russian and northern Norwegian school children: a comparison study in two arctic areas and the impact of environmental factors. J Eur Acad Dermatol Venereol. 2004; 18: 131-6.

16. Rönmark E, Perzanowski M, Platts-Mills T, and Lundbäck B. Incidence rates and risk factors for asthma among school children: a 2-year follow-up report from the obstructive lung disease in Northern Sweden (OLIN) studies. Respir Med. 2002; 96: 1006-13.

17. Hedman L, Bjerg A, Lundbäck B, and Rönmark E. Conventional epidemiology underestimates the incidence of asthma and wheeze-a longitudinal population-based study among teenagers. Clin Transl Allergy. 2012; 2: 1.

18. Kälvesten L, and Bråbäck L. Time trend for the prevalence of asthma among school children in a Swedish district in 1985-2005. Acta Paediatr. 2008; 97: 454-8.

19. Schernhammer ES, Vutuc C, Waldhör T, and Haidinger G. Time trends of the prevalence of asthma and allergic disease in Austrian children. Pediatr Allergy Immunol. 2008; 19: 125-31.

20. Bjerg-Bäcklund A, Bäcklund AB, Perzanowski MS, Platts-Mills T, Sandström T, Lundbäck B, and Rönmark E. Asthma during the primary school ages--prevalence, remission and the impact of allergic sensitization. Allergy. 2006; 61: 549-55.

21. Larsson M, Hägerhed-Engman L, Sigsgaard T, Janson S, Sundell J, and Bornehag CG. Incidence rates of asthma, rhinitis and eczema symptoms and influential factors in young children in Sweden. Acta Paediatr. 2008; 97: 1210-5.

22. Ballardini N, Kull I, Lind T, Hallner E, Almqvist C, Ostblom E, et al. Development and comorbidity of eczema, asthma and rhinitis to age 12 - data from the BAMSE birth cohort. Allergy. 2012; Feb 16.

23. Asher MI, Stewart AW, Wong G, Strachan DP, García-Marcos L, Anderson HR, and the ISAAC Phase Three Study Group. Changes over time in the relationship between symptoms of asthma, rhinoconjunctivitis and eczema: A global perspective from the International Study of Asthma and Allergies in Childhood (ISAAC). Allergol Immunopathol (Madr). 2012; Jan 30.

24. Peroni DG, Piacentini GL, Alfonsi L, Zerman L, Di Blasi P, Visona' G, et al. Rhinitis in pre-school children: prevalence, association with allergic diseases and risk factors. Clin Exp Allergy. 2003; 33: 1349-54.

25. Anthracopoulos MB, Pandiora A, Fouzas S, Panagiotopoulou E, Liolios E, and Priftis KN. Sex-specific trends in prevalence of childhood asthma over 30 years in Patras, Greece. Acta Paediatr. 2011; 100: 1000-5. 
26. Stapleton M, Howard-Thompson A, George C, Hoover RM, and Self TH. Smoking and asthma. J Am Board Fam Med. 2011; 24: 313-22.

27. Weiland SK, Hüsing A, Strachan DP, Rzehak P, Pearce N, and ISAAC Phase One Study Group. Climate and the prevalence of symptoms of asthma, allergic rhinitis, and atopic eczema in children. Occup Environ Med. 2004 ;61: 609-15.

28. Remes ST, Pekkanen J, Remes K, Salonen RO, and Korppi M. In search of childhood asthma: questionnaire, tests of bronchial hyperresponsiveness, and clinical evaluation. Thorax. 2002; 57: 120-6.

29. Rönmark EP, Ekerljung L, Lötvall J, Torén K, Rönmark E, and Lundbäck B. Large scale questionnaire survey on respiratory health in Sweden: effects of late- and non-response. Respir Med. 2009; 103: 1807-15. 